\title{
Cost and quality of life of overlooked eye care needs of children
}

This article was published in the following Dove Press journal: Risk Management and Healthcare Policy

\author{
Monali S Malvankar-Mehta ${ }^{1,2}$ \\ Ryan Wilson ${ }^{3}$ \\ Erik Leci ${ }^{3}$ \\ Kelly Hatch ${ }^{4}$ \\ Sapna Sharan'
}

'Department of Ophthalmology, Ivey Eye Institute, St. Joseph's Hospital, ${ }^{2}$ Department of Epidemiology and Biostatistics, ${ }^{3}$ Schulich School of Medicine and Dentistry, ${ }^{4}$ Allyn \& Betty Taylor Library, Natural Sciences Centre, The University of Western Ontario, London, ON, Canada
Correspondence: Monali S

Malvankar-Mehta

Department of Ophthalmology, Ivey

Eye Institute, St. Joseph's Hospital, 268

Grosvenor Street, London, ON N6A

$4 \mathrm{~V} 2$, Canada

$\mathrm{Tel}+\mathrm{I} 5196858500($ Ext 61288)

Fax +15196613766

Email Monali.Malvankar@schulich.uwo.ca
Background: The objective of this research was to conduct a systematic review and cost analysis to summarize, from the Ministry of Health perspective, the costs families might incur because of their child's prescription for refractive errors and amblyopia correction.

Methods: Databases including MEDLINE, Embase, BIOSIS, CINAHL, HEED, ISI Web of Science, and the Cochrane Library as well as the gray literature were searched. Systematic review was conducted using EPPI-Reviewer 4. Percentage difference in cost of glasses and patches per patient per various diagnoses were computed. The cost of glasses and patches was projected over a 5-year time horizon. Cost-utility analysis was performed.

Results: In total, 302 records were retrieved from multiple databases and an additional 48 records were identified through gray literature search. From these, a total of 14 studies (10,388 subjects) were eligible for quantitative analysis. The cost of glasses increased significantly for congenital cataract patients to US $\$ 1,820$, esotropia patients to US\$840, myopes to US\$411, amblyopes (mixed) to US\$916, anisometropes to US\$521, and patients with strabismus to US\$728 over a 5 -year period making them unaffordable for low-income families. Incremental cost of glasses of congenital cataract patients with delayed treatment was computed to be US\$1,690 per health utility gained. Incremental cost of glasses for high refractive error was US\$93 per health utility gained in non-compliant children. For amblyopia patients, incremental cost of glasses per quality-adjusted life years gained was US\$3,638.

Conclusion: Cost of corrective lenses is associated with significant financial burden and thus other means of mitigating costs should be considered. Eyesight problems in children are perceived as low-priority health needs. Thus, educational interventions on substantial visual deficits of not wearing glasses should be offered to families and governmental health agencies. Keywords: systematic review, amblyopia, prescription lens, utility, cost, quality-adjusted life years

\section{Introduction}

Although much of the developed world has some level of universal health coverage, many vital health services still burden patients with significant out-of-pocket costs. In ophthalmology, this is perhaps truest in the field of pediatric ophthalmology where specifically the cost of contact lenses and glasses for refractive errors is rarely covered by single payer universal health care programs yet frequently prescribed. ${ }^{1,2}$

This issue is compounded by several problems that are unique to pediatric eye care and eye pathology. Firstly, pediatric ophthalmic interventions and amblyopia treatment very commonly require refractive error correction in the form of eyeglasses, contact 
lenses, or intraocular lens implants. ${ }^{3}$ Secondly, the corrective lens prescription required to correct a child's vision can gradually change between follow-up appointments often requiring the purchase of multiple lenses. ${ }^{3}$ Additionally, most families have no/limited insurance and therefore find it very difficult to afford new or updated prescription lenses. ${ }^{4}$ Thus, many children can receive delayed vision correction that they have been prescribed. Lastly and perhaps most importantly, allowing a child to persist with an uncorrected refractive error for a prolonged period of time can result in irreversible amblyopia and permanent decline in visual acuity. ${ }^{5}$ All these points can be a source of great frustration to the provider for pediatric eye care.

The vast majority of information currently available on the costs surrounding pediatric eye care is from a health care spending perspective ${ }^{6,7}$ and does not consider out-of-pocket expenses the families of young children are expected to afford. Glasses break very frequently with activities of these young children and need to be replaced as frequently. This overburdens families and many tend to wait several weeks or months before finances are arranged or insurance benefits kick in. ${ }^{8}$ We know refractive errors and amblyopia can run in families, and many times multiple children in the family are also involved in simultaneous pediatric ophthalmology care.

We conducted a systematic review to summarize the costs a family might incur because of their child's prescription for vision and amblyopia correction and the overburden from a Ministry of Health perspective. Additionally, incremental cost per incremental effectiveness due to poor vision is considered. For the systematic review, multiple bibliographic databases were searched.

\section{Methods}

\section{Search strategy and selection criteria}

In this project, we adhered to the Preferred Items for Systematic Reviews and Meta-Analyses (PRISMA) guidelines. ${ }^{9}$ Literature, including published and unpublished scientific work, was systematically reviewed, and the following bibliographic databases were searched from January 2000 to May 2017: MEDLINE (OVID and PubMed), EMBASE (OVID), BIOSIS Previews (Thomson-Reuters), CINAHL (EBSCO), Health Economic Evaluations Database (HEED), ISI Web of Science (Thomson-Reuters), and the Cochrane Library (Wiley). Database-specific subject headings and key words were employed in the search strategy. The searches were modified to accommodate the unique terminology and syntax of each database. Additionally, all synonyms were considered with the help of information specialist (KH).
OVID AutoAlerts were set up to send monthly updates with any new literature.

Gray literature was identified by searching the conference abstracts of various meetings including the Canadian Ophthalmology Society meeting, American Association of Pediatric Ophthalmology and Strabismus, American Academy of Ophthalmology annual meeting, European Society of Ophthalmology, and the Association for Research in Vision and Ophthalmology annual meeting. The ProQuest Dissertations and Theses databases and the Canadian Health Research Collection (Ebrary) were also searched for relevant content. Google and other Internet search engines were used to search for additional web-based materials and information.

\section{Inclusion criteria}

Inclusion criteria were as follows: 1) publication in English language, 2) pediatric population between the age of 3 and 10 years, 3) publication dates from 2000 and onwards, and 4) journal articles, systematic reviews, meta-analysis, cost analysis, cost-utility analysis, cost-effectiveness analysis, multicenter studies, randomized controlled trials, nonrandomized studies including cohort studies (retrospective, prospective), clinical trials, and comparatives studies. There was no limit set by geography or country where the study was carried out. Figure 1 summarizes the PRISMA flow diagram for including studies for meta-analysis.

\section{Screening}

In total, 302 records were retrieved from multiple databases and additional 48 records were identified through gray literature search. These records were imported to EPPI-Reviewer 4 gateway (by EPPI-Centre, Social Science Research Unit, the Institute of Education, University of London, UK) to remove duplicates. After removing duplicates, 286 records were included for the three-level screening process (Figure S1). Level 1 screening involved reviewing titles, Level 2 screening reviewed abstracts, and Level 3 screening involved full-text reviews of each included study by two reviewers, independently (RW and EL). At each level, agreement for inclusion between the two reviewers was assessed by Cohen's kappa ( $\kappa)$ coefficient. Articles were included for the next level of screening if both the reviewers agreed. Differences between the reviewers were discussed and resolved by consensus. In cases where consensus was not achieved, a third reviewer (MMM) provided a decision. After screening, 48 records were assessed for eligibility. From these, a final total of 14 studies were found eligible for our quantitative analysis (Table 1). 


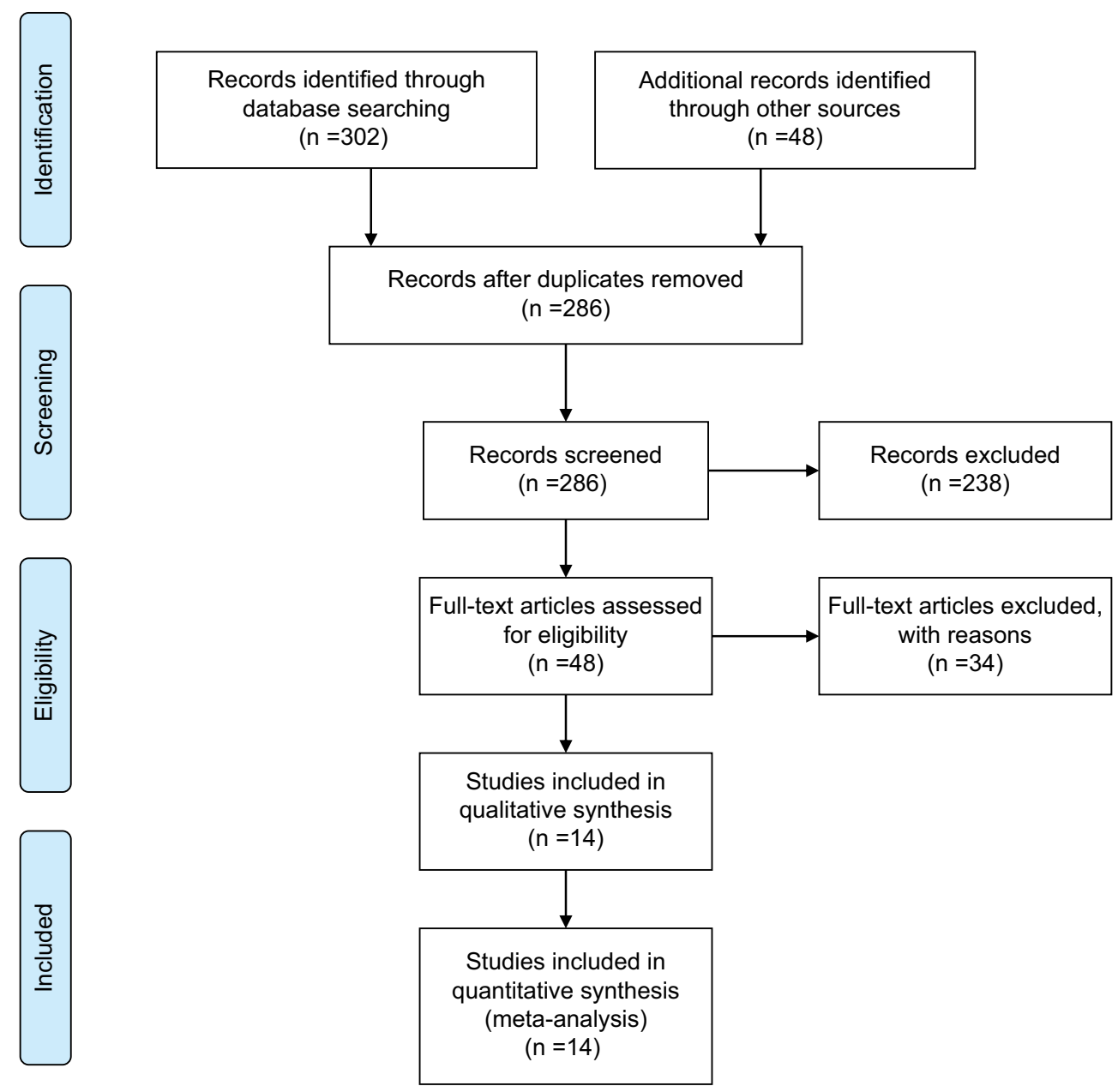

Figure I PRISMA flow diagram.

Note: Reprinted from Moher D, Liberati A, Tetzlaff J, Altman DG, The PRISMA Group (2009). Preferred Reporting Items for Systematic Reviews and Meta-Analyses: The PRISMA Statement. PLoS Med 6(6): el 000097. (C) 2009 Moher et al. ${ }^{29}$

Abbreviation: PRISMA, Preferred Items for Systematic Reviews and Meta-Analyses.

Table I Baseline characteristics of included studies

\begin{tabular}{|c|c|c|c|c|c|c|}
\hline \multirow[t]{2}{*}{ Study } & \multirow[t]{2}{*}{ Study design } & \multirow[t]{2}{*}{ Study location } & \multirow[t]{2}{*}{ Diagnosis } & \multirow{2}{*}{$\begin{array}{l}\text { Sample } \\
\text { size }\end{array}$} & \multicolumn{2}{|c|}{ Age (years) } \\
\hline & & & & & Mean & SD \\
\hline Awan et $\mathrm{al}^{17}$ & Cohort study & UK & Strabismus, (mixed) amblyopia, anisometropia & 321 & 4.1 & 1.73 \\
\hline Carrigan et al ${ }^{12}$ & RCT & USA & Aphakia post-congenital cataract removal & 114 & 0.292 & 0.104 \\
\hline Costello et $\mathrm{al}^{13}$ & Chart review & USA & Esotropia & 48 & 3.8 & 1.5 \\
\hline Frick et $\mathrm{al}^{20}$ & CE analysis & India & Refractive error & - & 11 & 2 \\
\hline Ghasia and Tychsen ${ }^{16}$ & CE analysis & USA & Refractive error & 87 & 10.1 & 4.56 \\
\hline König and Barry ${ }^{18}$ & CE analysis & Germany & Amblyopia & - & 3 & - \\
\hline Kruger et al ${ }^{15}$ & Cost analysis & USA & Congenital cataract & 114 & 0.25 & 1.5 \\
\hline Li et $\mathrm{al}^{21}$ & Cohort study & $\begin{array}{l}\text { People's Republic of } \\
\text { China }\end{array}$ & Refractive error & 597 & 14.7 & 0.8 \\
\hline Lim et $\mathrm{al}^{22}$ & Cohort study & Singapore & Myopia & 301 & 14.5 & 1.25 \\
\hline Magnusson and Persson ${ }^{19}$ & CE analysis & Sweden & Congenital cataract & - & - & - \\
\hline Stager et al $\left.\right|^{14}$ & Cost analysis & USA & Congenital cataract & - & - & - \\
\hline Wedner et $\mathrm{al}^{23}$ & $\mathrm{RCT}$ & Tanzania & Refractive error & 6,904 & 14.4 & 1.75 \\
\hline Zhang et $\mathrm{al}^{4}$ & $\begin{array}{l}\text { Cross-sectional } \\
\text { study }\end{array}$ & USA & Refractive error & $\mathrm{I}, 794$ & 10.5 & 0.5 \\
\hline
\end{tabular}

Abbreviations: RCT, randomized clinical trial; CE analysis, cost-effectiveness analysis. 


\section{Data extraction}

Data were extracted from the 14 eligible articles using a data extraction form. The first reviewer extracted data from the included studies, and a second reviewer resolved errors or mistakes if any by reviewing the extracted data. Data extracted included study objective, design, location, inclusion and exclusion criteria, data collection technique, data collection period, total patients enrolled in and completed the study, refusal to consent, number of females, patient demographic characteristics, follow-up, diagnosis, cost of prescribed modality for vision correction, secondary cost to vision correction, visual outcome, and compliance.

For missing data, various pieces of available information (such as the range, $p$-value, and confidence interval) were utilized and converted to the common effect measure (treatment effect) - SD. Further, corresponding authors were also contacted for additional information. Using a Downs and Black checklist, ${ }^{10}$ each included article was independently appraised by the two reviewers for quality.

Our main findings of the systematic review have been summarized in a tabular form. Table 1 lists the characteristics of the extracted studies, including study design, study location, diagnosis, sample size, and age. Table 2 lists data on visual outcomes for various diagnoses, compliance to glasses and patches, percentage of parents/guardians not able to afford glasses, and parent's education status. Data on effectiveness, cost of glasses, and incremental cost-effectiveness ratio (ICER) are listed in Table 3.

\section{Cost data}

Percentage difference in the cost of glasses per patient was computed for various diagnosis compared to refractive error. Additionally, percentage difference in the cost of patches per patient was computed for various diagnosis compared to anisometropia. Cost of glasses, contact lenses, and patches were projected over a 5-year time horizon assuming a child of age 4 years is diagnosed and he/she continues to wear glasses, contact lenses, patches, etc., until the age of 9 years.

\section{Effectiveness data}

Effectiveness or quality of life due to amblyopia, high refractive error in non-compliant children, and congenital cataract cases with delayed treatment was obtained from the literature. Additionally, ICER for each diagnosis was computed using formula from the literature ${ }^{11}$ assuming excellent quality of life (utility equals 1 ) for healthy patients incurring zero cost.

Table 2 Visual outcome and compliance reported in included studies

\begin{tabular}{|c|c|c|c|c|c|}
\hline Study & Diagnosis & $\begin{array}{l}\text { Visual outcome } \\
\text { (\% of children) }\end{array}$ & Compliance to glasses & Compliance to patches & $\begin{array}{l}\text { Glasses not } \\
\text { affordable (\%) }\end{array}$ \\
\hline \multirow[t]{3}{*}{ Awan et $\mathrm{al}^{17}$} & Strabismus & $\begin{array}{l}20 / 20 \text { (I8.9); } 20 / 32 \\
(63.5) ; 20 / 40(83.8)\end{array}$ & Major problem & $\begin{array}{l}\text { Compliance decreased with treatment } \\
\text { duration }\end{array}$ & - \\
\hline & $\begin{array}{l}\text { (Mixed) } \\
\text { amblyopia }\end{array}$ & $\begin{array}{l}20 / 20(15.5) ; 20 / 32 \\
(44.8) ; 20 / 40(63.8)\end{array}$ & - & $\begin{array}{l}\text { Compliance decreased with treatment } \\
\text { duration }\end{array}$ & - \\
\hline & Anisometropia & $\begin{array}{l}20 / 20(18.7) ; 20 / 32 \\
(68.1) ; 20 / 40(76.9)\end{array}$ & - & $\begin{array}{l}\text { Compliance decreased with treatment } \\
\text { duration }\end{array}$ & - \\
\hline Costello et $\mathrm{al}^{13}$ & Esotropia & - & $\begin{array}{l}2 \% \text { wore glasses }<10 \% \text { of } \\
\text { the time; } 14 \% \text { wore glasses } \\
>50 \% \text { but }<90 \% \text { of the } \\
\text { time; } 82 \% \text { wore glasses } \\
>90 \% \text { of the time }\end{array}$ & $\begin{array}{l}\text { I2\% wore patch or used occluding } \\
\text { drops }<10 \% \text { of the time; } 12 \% \text { wore } \\
\text { patch or used occluding drops }>50 \% \text { but } \\
<90 \% \text { of the time; } 76 \% \text { wore patch or } \\
\text { used occluding drops }>90 \% \text { of the time }\end{array}$ & - \\
\hline Li et $a^{21}$ & $\begin{array}{l}\text { Refractive } \\
\text { error }\end{array}$ & $20 / 20(100)$ & $\begin{array}{l}\text { Usually }(26 \%) ; \text { sometimes } \\
(63 \%) ; \text { seldom (II\%) }\end{array}$ & - & 40 \\
\hline Wedner et $\mathrm{al}^{23}$ & $\begin{array}{l}\text { Refractive } \\
\text { error }\end{array}$ & - & $\begin{array}{l}\text { Free spectacles compliance } \\
\text { (82\%); prescription only } \\
\text { compliance }(30 \%)\end{array}$ & - & 13.7 \\
\hline
\end{tabular}

Note: Dashes indicate that data was not available.

Table 3 Effectiveness due to amblyopia, refractive error, and congenital cataract

\begin{tabular}{|c|c|c|c|c|c|}
\hline Study & Diagnosis & Effectiveness data & Unit of effectiveness & $\begin{array}{l}\text { Cost of glasses } \\
\text { (US\$/patient) }\end{array}$ & ICER \\
\hline Ghasia and Tychsen ${ }^{16}$ & High RE (non-compliant children) & 0.88 & Utility & 11.12 & 92.67 \\
\hline König and Barry ${ }^{18}$ & Amblyopia (mixed) & 0.96 & QALYs & 145.52 & 3638 \\
\hline Magnusson and Persson ${ }^{19}$ & $\begin{array}{l}\text { Congenital cataract with IOL, cases with } \\
\text { delayed treatment }\end{array}$ & 0.8 & Utility & 338 & 1690 \\
\hline
\end{tabular}

Abbreviations: ICER, incremental cost-effectiveness ratio; RE, refractive error; QALYs, quality-adjusted life years; IOL, intraocular lens. 


\section{Results}

\section{Study characteristics}

The characteristics of the studies involved in statistical analysis included datasets from the US, ${ }^{4,12-16} \mathrm{UK},{ }^{17} \mathrm{Ger}$ many, ${ }^{18}$ Sweden, ${ }^{19}$ India, ${ }^{20}$ People's Republic of China, ${ }^{21}$ Singapore, ${ }^{22}$ and Tanzania. ${ }^{23}$ Further, the study design of the included works examined cost analysis, ${ }^{14,15}$ cost-effectiveness analysis, ${ }^{16,18-20}$ cohort studies, ${ }^{17,21,22}$ randomized controlled trials, ${ }^{12,23}$ chart review, ${ }^{13}$ and a cross-sectional study. ${ }^{4}$ Diagnosis in the studies included strabismus, amblyopia, anisometropia, esotropia, myopia, congenital cataract, and refractive errors (Table 1). Sample size in the included studies ranged from 48 to 6,904 patients.

Annual cost of the glasses per patient in included studies was highest for congenital cataract patients and lowest for refractive error patients. Annual cost of contact lenses per patients was highest for patients with congenital cataract.

Patients with visual acuity of $20 / 20$ varied from $15.5 \%$ to $100 \%, 20 / 32$ varied from $29.3 \%$ to $49.4 \%, 20 / 40$ from $8.8 \%$ to $20.3 \%$ (Table 2). Castanon Holguin et al reported a major problem of compliance to glasses for strabismus patients, which resonates with the literature. ${ }^{24} \mathrm{Li}$ et $\mathrm{al}^{21}$ reported that $40 \%$ of refractive error patients were not able to afford glasses. Compliance to patches decreased with duration of treatment.

\section{Cost-effectiveness analysis}

Table 3 lists effectiveness, cost of glasses per patient, and ICER for various diagnoses. For amblyopia patients, cost of glasses per quality-adjusted life years (QALYs) gained was US $\$ 3,638$. Cost of glasses for congenital cataract patients with delayed treatment was US $\$ 1,690$ per utility gained. Cost of glasses for high refractive error was US $\$ 92.67$ per utility gained in non-compliant children.

\section{Cost analysis}

In Figure 2, percentage difference in the annual cost of glasses per patient according to various diagnoses compared to refractive error was computed. Results indicated that the annual cost of glasses for patients with refractive error was 97\% less expensive compared to patients with congenital cataract, $94 \%$ less expensive compared to amblyopes (mixed), 93\% compared to esotropes, $92 \%$ compared to patients with strabismus, $89 \%$ compared to anisometropes, and $86 \%$ compared to myopes.

Percentage difference in the annual cost of patches (Figure 3) per patient according to various diagnoses compared to anisometropia was computed. Results indicated that the annual cost of patches for anisometropes was $92 \%$ less expensive compared to patients with congenital cataract, $84 \%$ less expensive compared to amblyopes (mixed), and $81 \%$ compared to patients with strabismus. This suggests that the annual cost of patches for low-income families with congenital cataract, amblyopia, or strabismus patients may represent a significant financial burden.

The cost of glasses (Figure 4) and patches (Figure 5) was projected over a 5-year time horizon. The cost of glasses increased considerably for congenital cataract patients to US $\$ 18,208$ making them unaffordable for economically challenged families over time. On the other hand, annual cost of glasses for refractive error patients increased to US\$55.6

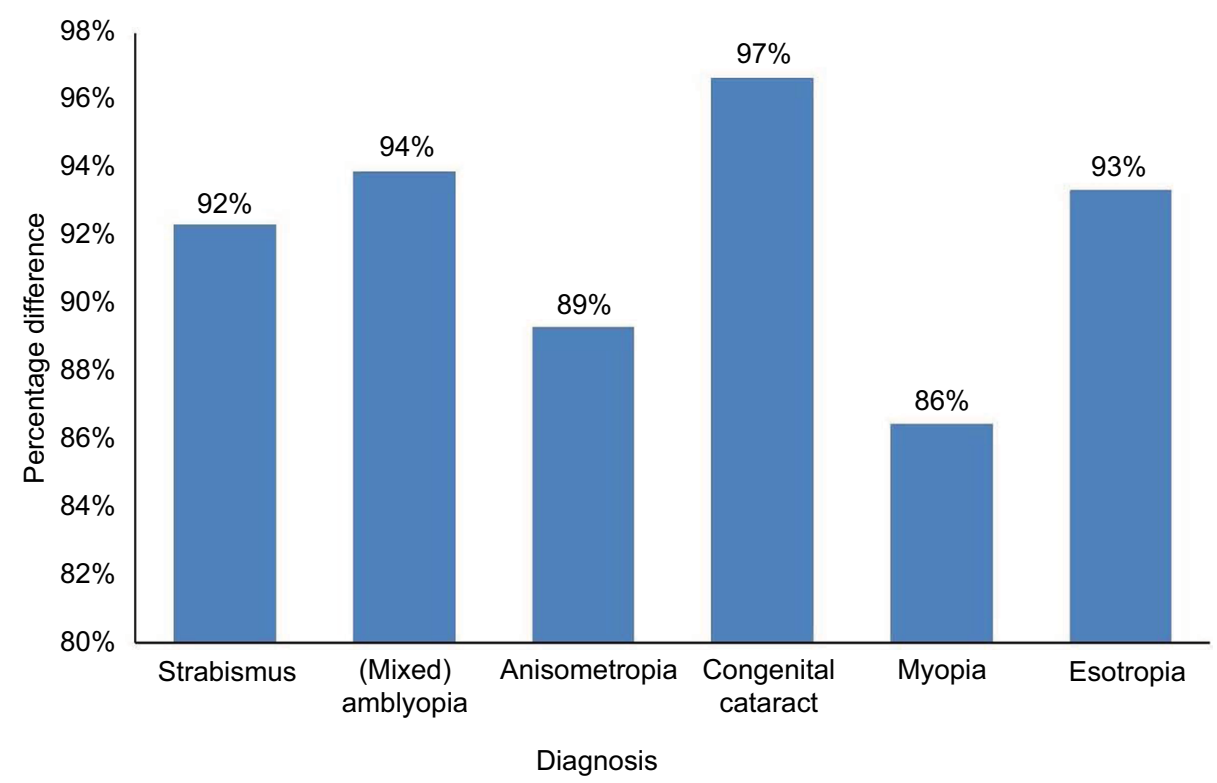

Figure 2 Percentage difference in cost (US\$) of glasses per patient according to various diagnosis compared to refractive error. 


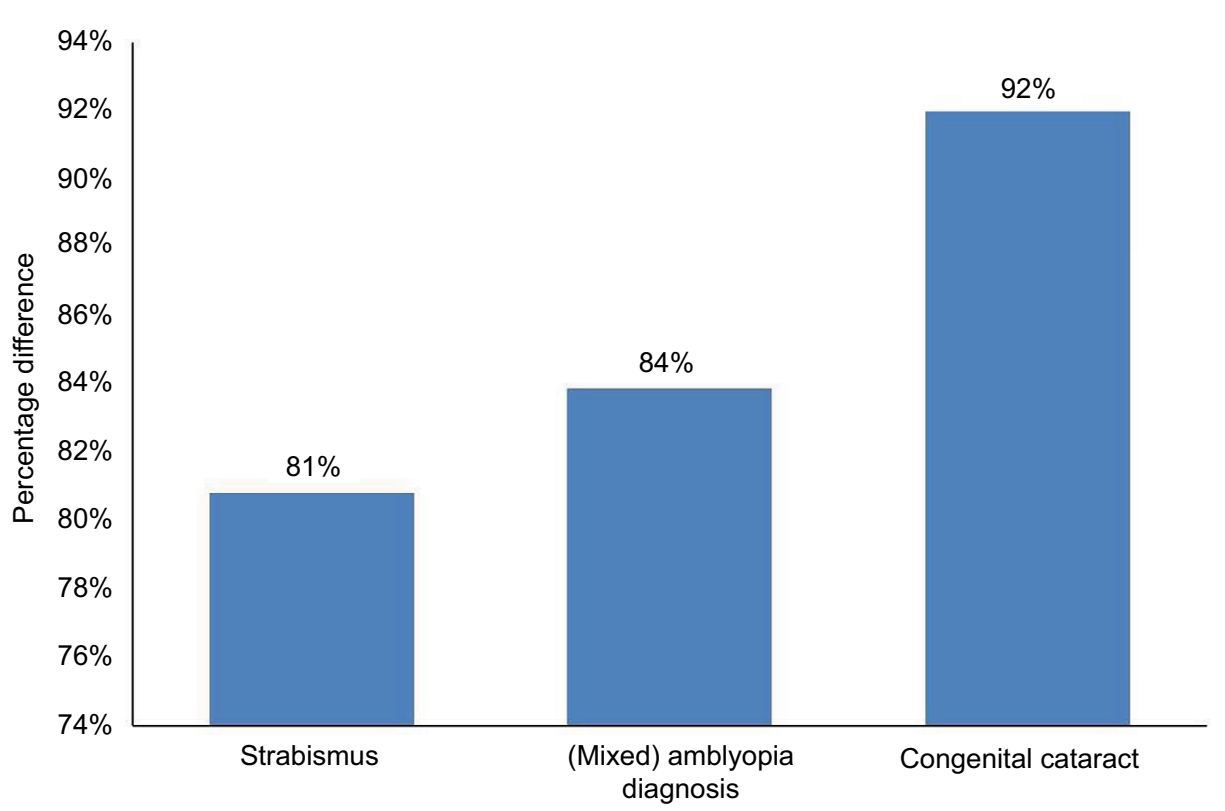

Figure 3 Percentage difference in cost (US\$) of patches per patient according to various diagnosis compared to anisometropia.

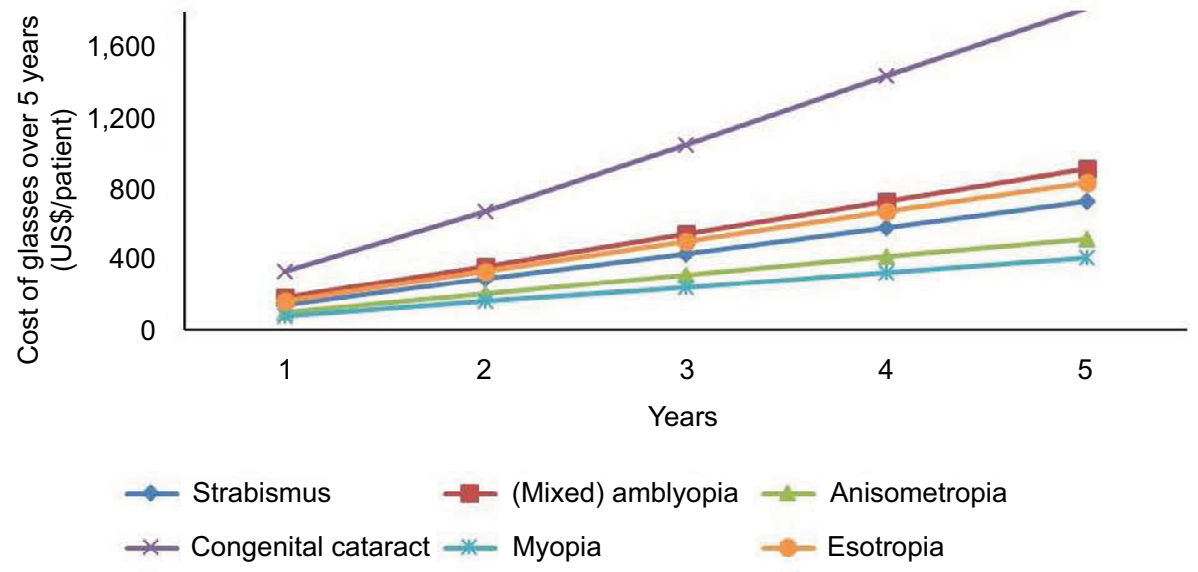

Figure 4 Cost (US\$) of glasses per patient according to diagnosis over a 5-year period.

over a 5-year time horizon. For esotropia patients, annual cost of glasses per patient increased to US $\$ 840$, for myopes to US\$410.5, for amblyopes (mixed) to US\$915.8, for anisometropes to US\$520.6, and for patients with strabismus to US\$727.6 over a 5-year period. Figure 5 shows that the annual cost for patching increased to US $\$ 945$, US $\$ 470.45$, US\$395.15, and US\$75.9 for patients with congenital cataract, amblyopia (mixed), strabismus, and anisometropia, respectively, over a 5-year time horizon.

\section{Discussion}

Our results indicated that for amblyopia patients, cost of glasses per QALYs gained was US\$3,638. Cost of glasses for congenital cataract patients with delayed treatment was
$\$ 1,690$ per utility gained. Additionally, yearly cost of glasses and patches per patient increased considerably over time for congenital cataract, amblyopia, and strabismus patients. Our results suggest that the annual cost of glasses for pediatric eye patients from low-income families - if covered or discounted - may have a long-lasting impact in enhancing patient's health-related quality of life.

A significant strength of our analysis stems from the fact that all the included studies had coherent results of improvement in visual outcomes posttreatment. There was heterogeneity between studies. This degree of heterogeneity could be a consequence of several factors, including consistency in the way the procedures were performed, geographic location, available facilities, follow-up period, 


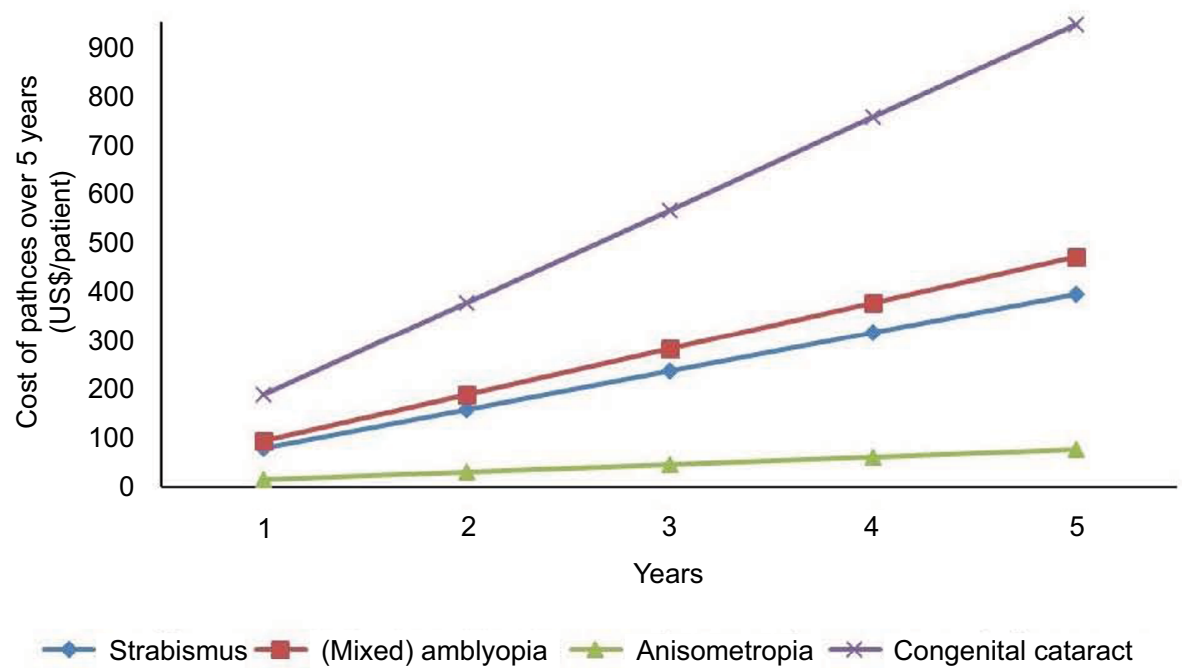

Figure 5 Cost (US\$) of patches per patient according to diagnosis over a 5-year period.

rates of compliance, and the year in which the study was conducted. On the other hand, our purpose was to quantitatively assemble the available data on this rather unknown subject. Second, the quality of the included studies was accessed using a Downs and Black checklist, ${ }^{10}$ and we did find high-, medium-, and poor-quality studies. However, we included all studies, irrespective of their quality, because of the limited number of articles we encountered on this topic. We found limited information on preoperative and postoperative contrast sensitivity, stereopsis, and astigmatism to conduct our quantitative analysis, and thus these characteristics were excluded from the analysis. It was also not the purpose of the study. Third, cost-utility analysis of observational studies is influenced by inherent bias in the included articles. ${ }^{25}$ For example, a multitude of other factors - income status, socioeconomic status, previous ocular and non-ocular surgeries, family history, other ocular and nonocular diseases, preoperative and postoperative medications, number of medications - can influence the estimates in the original studies. Fourth, many studies had to be excluded due to lack of necessary information. Fifth, only studies published in English were included. If all the excluded studies had been considered, such an inclusion would unlikely make a considerable impact since our cost-utility analysis agreed with published studies.

In sum, our results showed that there is considerable cost to patient per health utility gained and annual cost of glasses per patient increased considerably. Thus, patients may use less costly frames instead of buying expensive trendy frames to help mitigate the cost. ${ }^{26}$ If a child's prescription changes often, then new lenses in the old frame may help save some money. ${ }^{27}$
Further, other means of reducing cost such as covering for the first pair of glasses, educating parents about substantial visual deficits of not wearing glasses, or providing glasses at a discounted price for low-income families should be considered by health care planning authorities in governments all over the world.

\section{Disclosure}

The authors report no conflicts of interest in this work.

\section{References}

1. Ma JJ, Morad Y, Mau E, Brent HP, Barclay R, Levin AV. Contact lenses for the treatment of pediatric cataracts. Ophthalmology. 2003;110(2):299-305.

2. Care MoHaL-T. OHIP coverage for eye care services. Available from: http://www.health.gov.on.ca/en/public/publications/ohip/eyecare.aspx. Accessed September 16, 2015.

3. Shotton K, Elliott S. Interventions for strabismic amblyopia. Cochrane Database Syst Rev. 2008;(2):CD006461.

4. Zhang X, Elliott MN, Saaddine JB, et al. Unmet eye care needs among U.S. 5th-grade students. Am J Prev Med. 2012;43(1):55-58.

5. Simons K, Preslan M. Natural history of amblyopia untreated owing to lack of compliance. Br J Ophthalmol. 1999;83(5):582-587.

6. Membreno JH, Brown MM, Brown GC, Sharma S, Beauchamp GR. A cost-utility analysis of therapy for amblyopia. Ophthalmology. 2002;109(12):2265-2271.

7. Arnold RW, Armitage MD, Gionet EG, et al. The cost and yield of photoscreening: impact of photoscreening on overall pediatric ophthalmic costs. J Pediatr Ophthalmol Strabismus. 2005;42(2):103-111.

8. Butler JA, Winter WD, Singer JD, Wenger M. Medical care use and expenditure among children and youth in the United States: analysis of a national probability sample. Pediatrics. 1985;76(4):495-507.

9. Moher D, Liberati A, Tetzlaff J, Altman DG; PRISMA Group. Preferred reporting items for systematic reviews and meta-analyses: the PRISMA statement. Ann Intern Med. 2009;151(4):264-269, W64.

10. Downs SH, Black N. The feasibility of creating a checklist for the assessment of the methodological quality both of randomised and nonrandomised studies of health care interventions. JEpidemiol Community Health. 1998;52(6):377-384. 
11. Drummond MF, Sculpher MJ, Claxton K, Stoddart GL, Torrance GW. Methods for the Economic Evaluation of Health Care Programmes. New York: Oxford University Press; 2015.

12. Carrigan AK, DuBois LG, Becker ER, Lambert SR; Infant Aphakia Treatment Study Group. Cost of intraocular lens versus contact lens treatment after unilateral congenital cataract surgery: retrospective analysis at age 1 year. Ophthalmology. 2013;120(1):14-19.

13. Costello PA, Simon JW, Jia Y, Lininger LL. Acquired esotropia: subjective and objective outcomes. JAAPOS. 2001;5(3):193-197.

14. Stager DR Jr, Felius J, Beauchamp GR. Congenital cataract cost. Ophthalmology. 2009;116(12):2484.e1-e2.

15. Kruger SJ, DuBois L, Becker ER, et al; Infant Aphakia Treatment Study Group. Cost of intraocular lens versus contact lens treatment after unilateral congenital cataract surgery in the infant aphakia treatment study at age 5 years. Ophthalmology. 2015;122(2):288-292.

16. Ghasia F, Tychsen L. Utility values for surgical treatment of high refractive errors in children. JAAPOS. 2007;11(1):89.

17. Awan M, Proudlock FA, Grosvenor D, Choudhuri I, Sarvanananthan N, Gottlob I. An audit of the outcome of amblyopia treatment: a retrospective analysis of 322 children. Br J Ophthalmol. 2010;94(8): 1007-1011.

18. König HH, Barry JC. Cost effectiveness of treatment for amblyopia: an analysis based on a probabilistic Markov model. Br J Ophthalmol. 2004;88(5):606-612.

19. Magnusson G, Persson U. Screening for congenital cataracts: a cost-consequence analysis of eye examination at maternity wards in comparison to well-baby clinics. Acta Paediatr. 2005;94(8): 1089-1095.
20. Frick KD, Riva-Clement L, Shankar MB. Screening for refractive error and fitting with spectacles in rural and urban India: cost-effectiveness. Ophthalmic Epidemiol. 2009;16(6):378-387.

21. Li L, Song Y, Liu X, et al. Spectacle acceptance among secondary school students in rural China: the Xichang Pediatric Refractive Error Study (X-PRES)—report 5. Invest Ophthalmol Vis Sci. 2008;49(7):2895-2902.

22. Lim MC, Gazzard G, Sim EL, Tong L, Saw SM. Direct costs of myopia in Singapore. Eye (Lond). 2009;23(5):1086-1089.

23. Wedner S, Masanja H, Bowman R, Todd J, Bowman R, Gilbert C. Two strategies for correcting refractive errors in school students in Tanzania: randomised comparison, with implications for screening programmes. Br J Ophthalmol. 2008;92(1):19-24.

24. Castanon Holguin AM, Congdon N, Patel N, et al. Factors associated with spectacle-wear compliance in school-aged Mexican children. Invest Ophthalmol Vis Sci. 2006;47(3):925-928.

25. Egger M, Davey Smith G, Schneider M, Minder C. Bias in meta-analysis detected by a simple, graphical test. BMJ. 1997;315(7109):629-634.

26. Optical L-K. Consumers guide to buying glasses 2016. Available from: https:/opticianworks.laramyk.com/the-consumers-guide-10-11-15/. Accessed November 16, 2016.

27. G. H. Eyeglasses: frequently asked questions. Available from: http://www. allaboutvision.com/faq/eyeglasses.htm. Accessed November 16, 2016.

28. Moher D, Liberati A, Tetzlaff J, Altman DG; The PRISMA Group. Preferred reporting items for systematic reviews and meta- analyses: the PRISMA statement. PLoS Med. 2009;6(6):e1000097.

29. Moher D, Liberati A, Tetzlaff J, Altman DG, The PRISMA Group. Preferred Reporting Items for Systematic Reviews and Meta-Analyses: The PRISMA Statement. PLoS Med. 2009: 6(6): e1000097. 


\section{Supplementary material}

Level 1 (title screening)

1) Is this a research study (not an editorial, opinion, case report, or a review article)?
a. Yes
b. No
c. Unclear

2) Does the study look at the prescription of corrective lenses in pediatric populations?
a. Yes
b. No
c. Unclear

3) Does the study look directly at the associated costs of corrective lenses?
a. Yes
b. No
c. Unclear

Level 2 (abstract screening)

1) Does the study look at prescription corrective lenses for pediatric patients with amblyopia, strabismus, or accommodative esotropia?
a. Yes
b. No
c. Unclear

2) Does the study consider a sample size of 20 or more patients?
a. Yes
b. No
c. Unclear

\section{Level 3 (full-text screening)}

1) Is the study specifically focused on the direct and/or indirect cost of corrective lenses?
a. Yes
b. No
c. Unclear

Figure SI Screening questions

\section{Publish your work in this journal}

Risk Management and Healthcare Policy is an international, peer-reviewed, open access journal focusing on all aspects of public health, policy, and preventative measures to promote good health and improve morbidity and mortality in the population. The journal welcomes submitted papers covering original research, basic science, clinical and epidemiological studies, reviews and evaluations, guidelines, expert opinion and commentary, case reports and extended reports. The manuscript management system is completely online and includes a very quick and fair peerreview system, which is all easy to use. Visit http://www.dovepress.com/ testimonials.php to read real quotes from published authors.

Submit your manuscript here: https://www.dovepress.com/risk-management-and-healthcare-policy-journal 